\title{
Erratum
}

In the article "Molecular phylogeny of the tribe Philodryadini Cope, 1886 (Dipsadidae: Xenodontinae): Rediscovering the diversity of the South American Racers", http://doi.org/10.11606/18070205/2020.60.53, published in the Journal Papéis Avulsos de Zoologia, Volume 60: e20206053,

\section{In the Acknowledgments:}

\section{Where you read:}

We are in dept with the curators and institutions staff who granted us access to the samples for obtention of molecular evidence. We thank J. Battilana for her help during acquisition of molecular data. We thank F. Curcio and L.J. Vitt for providing photographs of $P$. nattereri, X. boulengeri and P. olfersii used in Fig. 2. We are grateful for the comments from two reviewers whose suggestions improved this manuscript. This study was financed in part by the Coordenação de Aperfeiçoamento de Pessoal de Nível Superior - Brasil (CAPES) - Finance Code 001. FGG was supported by FAPESP (grants 2012/08661-3 and 2016/13469-5). HZ, MTR, and SLB are grateful to Conselho Nacional de Desenvolvimento Científico e Tecnológico (CNPq) for continuing financial support. SLB and MTR were supported by FAPERGS and FAPESP (grants 2003/10335-8 and 2011/50146-6), respectively. This study was funded by Fundação de Amparo à Pesquisa do Estado de São Paulo (FAPESP grants 2011/50206-9 and 2016/50127-5) to HZ.

\section{Read it:}

We are in dept with the curators and institutions staff who granted us access to the samples for obtention of molecular evidence. We thank C. Sarturi (PUCRS), J. Battilana (MZUSP), and N. da Rós (LETA) for their help during the acquisition of molecular data. We thank F. Curcio and L.J. Vitt for providing photographs of $P$. nattereri, $X$. boulengeri and $P$. olfersii used in Fig. 2. We are especially thankful to R. Bernils and R. Rabello-Reis (UFES) for the tissue sample of Chlorosoma laticeps (ICMBio/SISBio permit number 57585). We are grateful for the comments from two reviewers whose suggestions improved this manuscript. This study was financed in part by the Coordenação de Aperfeiçoamento de Pessoal de Nível Superior - Brasil (CAPES) - Finance Code 001. FGG was supported by FAPESP (grants 2012/08661-3 and 2016/13469-5). HZ, MTR, and SLB are grateful to Conselho Nacional de Desenvolvimento Científico e Tecnológico (CNPq) for continuing financial support. SLB and MTR were supported by FAPERGS and FAPESP (grants 2003/10335-8 and 2011/50146-6), respectively. This study was funded by Fundação de Amparo à Pesquisa do Estado de São Paulo (FAPESP grants 2011/50206-9 and 2016/50127-5) to HZ. 